\section{D) Check for updates}

Cite this: Phys. Chem. Chem. Phys., 2018, 20, 3847

DOI: $10.1039 / c 8 c p 90018 c$

rsc.li/pccp

\title{
Correction: High-temperature X-ray diffraction and thermal expansion of nanocrystalline and coarse-crystalline acanthite $\alpha-\mathrm{Ag}_{2} \mathrm{~S}$ and argentite $\mathrm{\beta}-\mathrm{Ag}_{2} \mathrm{~S}$
}

\author{
S. I. Sadovnikov, ${ }^{a}$ A. I. Gusev, ${ }^{\star a}$ A. V. Chukin ${ }^{b}$ and A. A. Rempel ${ }^{a}$
}

Correction for 'High-temperature X-ray diffraction and thermal expansion of nanocrystalline and coarse-crystalline acanthite $\alpha-\mathrm{Ag}_{2} \mathrm{~S}$ and argentite $\beta-\mathrm{Ag}_{2} \mathrm{~S}$ ' by S. I. Sadovnikov et al., Phys. Chem. Chem. Phys., 2016, 18, 4617-4626.

The authors wish to draw the readers' attention to their previous related study, published in Physics of the Solid State, ${ }^{1}$ which should have been cited in this Physical Chemistry Chemical Physics paper.

The study published in this Physical Chemistry Chemical Physics paper contains new experimental X-ray diffraction data, differential thermal and thermogravimetric analysis (DTA-DTG) results and data on the acanthite-argentite phase transformation enthalpy. This Physical Chemistry Chemical Physics paper was accepted before the publication of ref. 1 but published after ref. 1. Therefore ref. 1 should have been cited in this Physical Chemistry Chemical Physics paper.

The authors regret not giving the correct attribution for Fig. 4, 6, 7, 8 and 9 in the paper, which were reproduced for the readers' information. The figures are reproduced below with the correct copyright permission text.

\footnotetext{
${ }^{a}$ Institute of Solid State Chemistry, Ural Branch of the Russian Academy of Sciences, Ekaterinburg 620990, Russia. E-mail: gusev@ihim.uran.ru

${ }^{b}$ Ural Federal University named after the First President of Russia B.N. Yeltsin, Ekaterinburg, 620002, Russia
} 

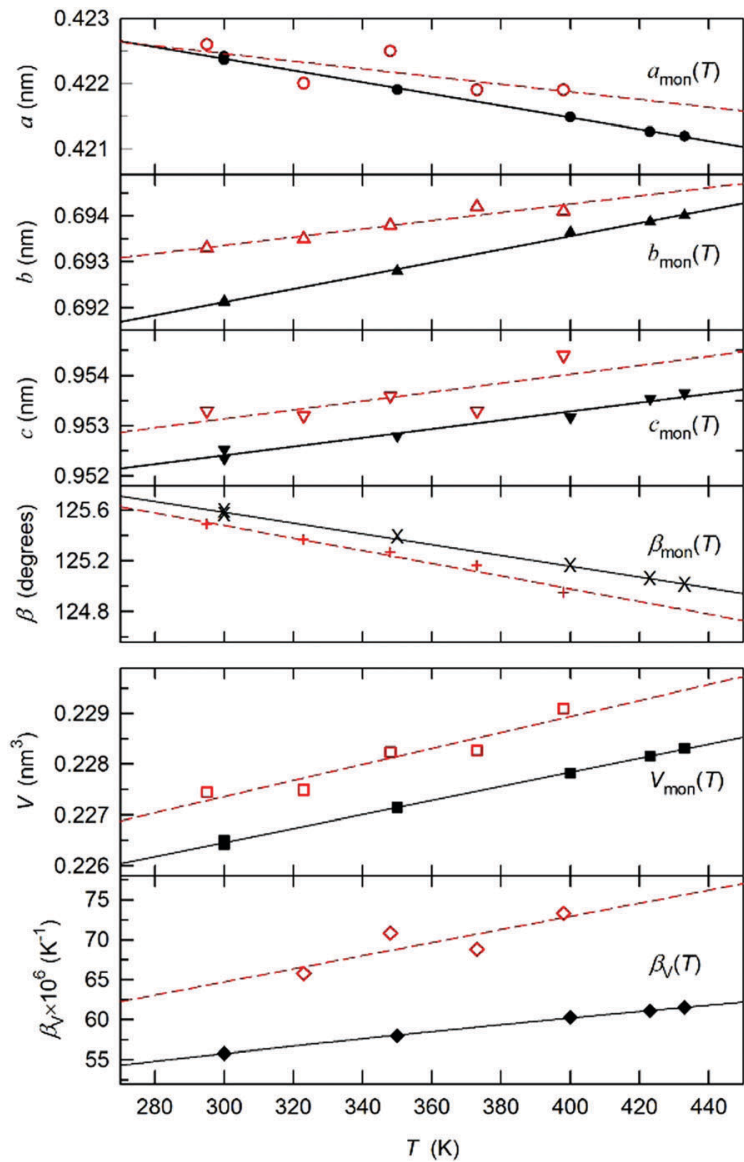

Fig. 4 The effect of temperature $T$ on the unit cell parameters $a, b, c, \beta$, and volume $V$, and on the volumetric thermal expansion coefficient $\beta_{V}$ of coarse- and nanocrystalline acanthite. The approximation of the experimental data by the solid line and the closed symbols $(\boldsymbol{\cup}),(\mathbf{\Lambda}),(\mathbf{\nabla}),(\times),(\mathbf{\square})$, and $(\bullet)$ corresponds to coarse-crystalline acanthite and the approximation by the dotted line and the open symbols $(O),(\Delta),(\nabla),(+),(\square)$, and $(\diamond)$ corresponds to nanocrystalline acanthite. Reproduced from ref. 1 with permission from Springer. 


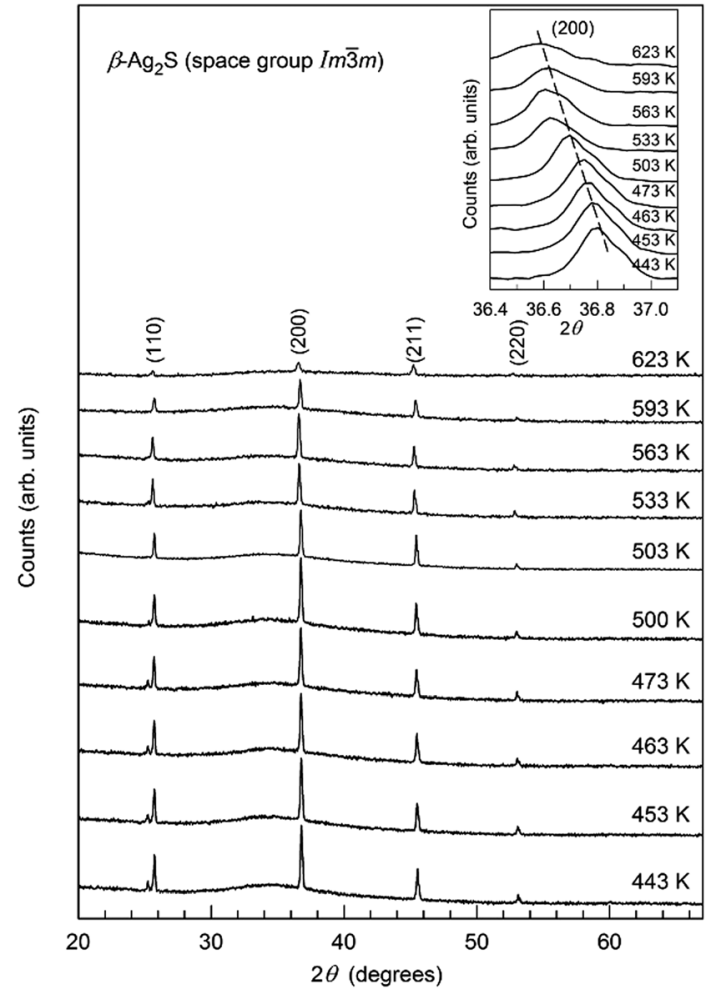

Fig. 6 Evolution of XRD patterns of coarse-crystalline argentite $\beta-\mathrm{Ag}_{2} \mathrm{~S}$ in the temperature range of $446-623 \mathrm{~K}$. The inset shows a systematic displacement of the (200) diffraction reflection of bcc argentite with increase of measuring temperature. Reproduced from ref. 1 with permission from Springer.

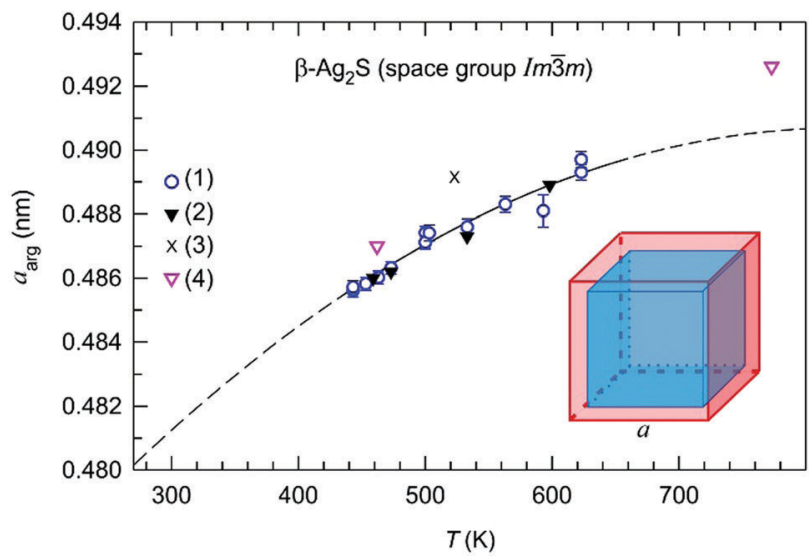

Fig. 7 Dependence of the lattice constant $a_{\text {arg }}$ of argentite $\beta-\mathrm{Ag}_{2} \mathrm{~S}$ on the temperature $T$ : (1) data of present work; (2), (3), and (4) data, 22,24,27 respectively. The approximations of measured lattice constant $a_{\text {arg }}$ by the function (10) in the temperature range of $440-660 \mathrm{~K}$ is shown by solid lines. Reproduced with some changes from ref. 1 with permission from Springer. 


.

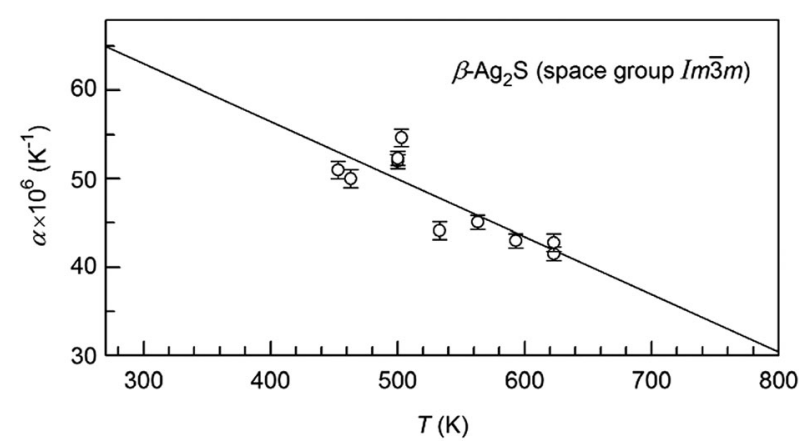

Fig. 8 Temperature dependence of linear thermal expansion coefficient $\alpha_{\text {arg }}$ of argentite $\beta-\mathrm{Ag}_{2} \mathrm{~S}$ and its approximation by the function (12). Reproduced from ref. 1 with permission from Springer.

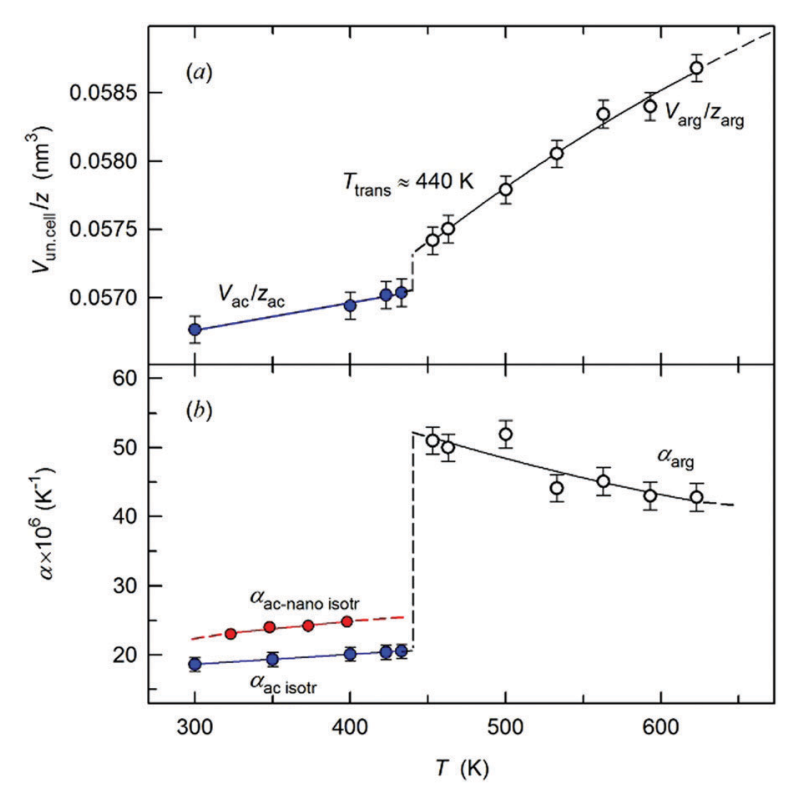

Fig. 9 The temperature dependencies of reduced volume $V_{\text {un.cell }} / z$ (a) and isotropic linear thermal expansion coefficient $\alpha$ (b) of silver sulfide in the of range 300-623 K. At $\sim 440 \mathrm{~K}$, there take place jumps of the reduced volume and the thermal expansion coefficient $\alpha$ attributed to the first-order acanthite-argentite phase transformation. Isotropic linear thermal expansion coefficient $\alpha_{\text {ac-nanoisotr }}$ of nanocrystalline acanthite $\alpha$-Ag $2 \mathrm{~S}$ is larger than $\alpha_{\text {acisotr }}$ of coarse-crystalline acanthite. Reproduced with changes from ref. 1 with permission from Springer.

The Royal Society of Chemistry apologises for these errors and any consequent inconvenience to authors and readers.

\section{References}

1 A. I. Gusev, S. I. Sadovnikov, A. V. Chukin and A. A. Rempel, Phys. Solid State, 2016, 58, 251-257. 